\title{
Research on the Implementation Path of Sports for Promoting the Cultivation of the Entrepreneurship of Higher Vocational Students
}

Yue Li*, Xiaoping Wang, Pingping Zhu

Changzhou Vocational and Technical College of Engineering, Changzhou 213164, Jiangsu Province, China

Funding: Supported by Jiangsu Provincial Innovation Project in 2020: Sports Exhibition Design and Derivative Development

Based on Sports Events.

\begin{abstract}
Since the slogan "Entrepreneurship by the masses, innovation by all" was put forward in 2014, innovation and entrepreneurship have gradually become an important basis for vocational education reform. Especially in recent years, under the background of increasing employment pressure of higher vocational students, innovation and entrepreneurship education has been widely integrated into all aspects of education and teaching in higher vocational colleges, which not only promotes the improvement of the comprehensive professional ability of higher vocational students, but also Provide necessary assistance for its subsequent good employment and development. In teaching, teachers can try to incorporate the spirit of sports into the cultivation of innovation and entrepreneurship capabilities, so as to improve the effectiveness of education and at the same time cultivate more innovative talents for the society. Based on this, this article will analyze the implementation path of sports to promote the cultivation of entrepreneurial spirit of higher vocational students, and propose some strategies for your colleagues' reference only.
\end{abstract}

Key words: Physical education; Higher vocational education; Entrepreneurship; Training path

Publication date: December, 2020

Publication online: 31 December, 2020

"Corresponding author: Yue Li, 97216659@qq.com

\section{Introduction}

Innovation is the soul of a nation, and entrepreneurship is the way to prosperity for the people. For the majority of vocational colleges, how to implement innovation and entrepreneurship education has become an urgent problem to be solved. In 2014, the Ministry of Education clearly stated that all major higher vocational colleges should gradually establish vocational, application-oriented, and dualcreation-oriented education goals. This also shows that higher vocational education should not only attach importance to professional theoretical teaching, but also combine professional characteristics, based on the national development situation and the employment needs of higher vocational students, and infiltrate innovation and entrepreneurship education into the education reform, especially to do a good job. Based on the practical teaching reform work of double innovation education, to achieve the two-way goal of improving teaching effectiveness and developing students' comprehensive ability. Sports spirit is similar to entrepreneurial spirit. It can effectively promote the further development of entrepreneurial spirit. Teachers should actively explore effective ways to integrate sports and entrepreneurial spirit while cultivating students' entrepreneurial spirit, so as to comprehensively improve students' entrepreneurial spirit level, and then comprehensively Improve the entrepreneurial success rate of vocational students. 


\section{Establishing a special institution to help innovation and innovation education}

In order to further strengthen the effect of double innovation education for vocational students and promote the reform of practical teaching, it is necessary for higher vocational colleges to set up special institutions around the reform of innovation and entrepreneurship teaching. Specifically, academic staff can be used to match-making, in conjunction with professional teachers, counselors, and staff from other functional departments carry out educational work aimed at innovation and entrepreneurship. At the same time, it is necessary to speed up the formulation of education implementation plans centered on dual innovation education, improve related work systems, and establish special dual innovation teaching and research offices, entrepreneurship incubation bases, entrepreneurship training classes and other entities. In addition, each department should also set up subordinate working groups, subject teachers or counselors can be responsible for innovation and practical teaching reforms, so as to finally form an innovation and entrepreneurship education system in the form of departmental coordination, professional autonomy and full-member interaction. The development of students' entrepreneurial spirit provides a good boost.

\section{Implementing the concept of student- oriented and lay the foundation of education}

Under the situation of in-depth advancement of quality education, all links of higher vocational education, including practical teaching and double innovation education, must take the studentoriented concept as the core, highlighting their subjectivity in the process of receiving education. Specifically, higher vocational colleges should focus on innovation and entrepreneurship education, speed up the preparation and establishment of innovative entrepreneurship education curriculum systems, and actively innovate curriculum teaching objectives and teaching design through ideas such as the promotion of innovation awareness, entrepreneurship method education, and the transmission of ideas and concepts, in order to improve the effectiveness of education. At the same time, while offering relevant courses, it is necessary to encourage all professional disciplines to actively carry out related double- creation education elective courses around innovation and entrepreneurship education, so that students can absorb professional knowledge while also expanding their own innovation and entrepreneurship knowledge reserves, thereby create a new pattern of "promoting double innovation education with professional education". In addition, we all know that a good team of teachers is an important guarantee for vocational education. Therefore, higher vocational colleges must do a good job in the selection and training of fulltime teachers. For example, professional teachers can be selected around counselors, ideological and political teachers, and regularly organize exchange meetings and seminars with the theme of innovation and innovation education, and strive to build a team of innovative and entrepreneurial teachers with strong guiding ability, high educational skills and good ideological literacy.

\section{Innovating the educational model and enrich the educational carrier}

Forming interest clubs nowadays, innovation and entrepreneurship have been widely recognized in higher vocational colleges, but how to combine innovation and innovation education to create a good educational environment and promote student exchanges and sharing has become the practice teaching reform in the majority of vocational colleges. In this regard, higher vocational colleges may wish to combine the cognitive characteristics and learning rules of higher vocational students, and adopt a fun-oriented way to innovate the education model. For example, it is possible to set up sports interest clubs with the content of dual innovation education around the teaching of physical education. Among them, the school supports the organization, students voluntarily sign up, and then through various methods such as "everyone forum", "program exchanges", "competitions" and other methods to give play to the educational auxiliary effect of sports clubs, thereby further arousing students' enthusiasm for innovation and innovation, so that they can grow together, innovate together and start a business together.

\section{Doing a good job in special training}

Departments of student education, employment, and youth work in higher vocational colleges should 
form a joint force with the education department, and actively carry out various forms of student special training activities centering on double innovation education. At the same time, they should cooperate with local social security, personnel, employment management, corporate services, and scientific and technological innovation and other institutions regularly organize corresponding special training meetings and symposiums around the total value of "encourage innovation and serve entrepreneurship". In particular, make good use of the relevant experiences of successful entrepreneurs and employment mentors to encourage higher vocational students to innovate entrepreneurship enables them to consciously establish a good outlook on learning and career. In addition, colleges and majors should also combine their own educational characteristics and rely on school-enterprise cooperation to establish oncampus laboratories, practice bases, and off-campus practice venues, so as to provide higher vocational students with better learning and practice and double innovation practice. The venue is guaranteed, and these bases can specifically hire successful people or outstanding entrepreneurial graduates as consultants to provide students with scientific guidance for better innovation and entrepreneurship operations and attempts.

\section{Actively introducing competitions}

In the practical teaching of higher vocational colleges, skill competitions and innovation and entrepreneurship training are important links. They not only have a direct impact on the development of students' practical ability, comprehensive literacy, innovation awareness and entrepreneurial quality, but also deepen education reform and improve effective factors for educating people and promoting the integration of production, education and research. In this regard, the majority of vocational colleges should focus on academic competitions at the national, provincial, and municipal levels, and actively guide students to actively participate in social research, scientific and technological invention, etc. through publicity, guidance, practice, work cultivation, and competition display. The paper is innovating to create a good atmosphere for innovation and innovation education. At the same time, the majority of higher vocational colleges must combine their professional characteristics, unite with higher vocational student associations, and actively organize skills competitions with professional education as the core, and introduce corporate forces in the process, such as organizing professional competitions with related companies, and the integration of competition, research and employment will arouse students' enthusiasm for innovation and innovation, and make the innovation and innovation competition more normalized, scientific, standardized and institutionalized. Finally, for the students and works that performed well in the competition, the school should provide them with an opportunity to declare scientific and technological innovation projects, carefully select some highquality innovation projects for project support, and give full play to the guiding role of professional teachers to improve double innovation results output.

\section{Focusing on practical exercises and build a stage for students}

Social practice, as an important way for vocational students to observe society, understand society, practice skills, and improve themselves, can serve as a good carrier for innovation and innovation education. Therefore, the majority of higher vocational colleges should pay attention to students' practical exercises, and combine innovation and innovation education to further improve students' ability to analyze and deal with practical problems, so that they can gain the development of innovative spirit and entrepreneurial quality while gaining professional skills experience. Specifically, when implementing innovation and innovation education, higher vocational colleges should infiltrate the concepts of brand building, project implementation, and social operation into students' social practice, adhering to the principles of setting up projects on demand, building groups based on projects, and two-way benefits. While serving local cultural undertakings and economic development, promote innovation and innovation education. For example, higher vocational colleges can encourage students to closely unite with local cultural undertakings and economic development during social practice during holidays or professional internships, and actively engage enterprises, government agencies, and other themes, focusing on "school-enterprise cooperation" and "political "school cooperation" builds a practical 
platform for students. For example, colleges and universities can link up with relevant companies and cooperate with them around students' practical innovations, and strive for opportunities for work practice and professional scientific research that are compatible with their own majors. In this way, they can increase their knowledge and show their style in social practice, laying a foundation for their practice and the development of double innovation ability.

\section{Guiding self-employment and strength- ening service}

With the current cognition of vocational students and the changes of the times, more and more vocational students have begun to devote themselves to selfemployment. However, as far as the actual situation is concerned, those vocational students who have just stepped into the society are generally unable to realize their entrepreneurial dreams in this "ivory tower". There are problems with their own knowledge and experience as well as the entrepreneurial environment. And family factors and other issues. Faced with this situation, if higher vocational colleges ignore it, it is easy to diminish students' interest in innovation and entrepreneurship. Therefore, in order to eliminate the encouragement of higher vocational students for innovation and entrepreneurship, higher vocational colleges should do a good job of guiding selfemployment and strengthen the service to students. For example, they can link various off-campus resources to actively build entrepreneurial incubation bases and crowd-creation platforms, and set up a special student venture capital to provide students with entrepreneurial guidance with a professional team of tutors. In addition, higher vocational colleges should actively encourage students to apply for entrepreneurship certificates and give them the green light for funding, venues, policies, etc. If their entrepreneurial projects and entrepreneurial plans are of better quality, the school can provide them with full service and support. Finally, higher vocational colleges should combine the actual needs of entrepreneurial projects and actively invite legal professional teachers to provide legal consulting and policy consulting services for students' entrepreneurial practice, so as to provide them with better protection for their own entrepreneurship and education for innovation and entrepreneurship. The practical effect is even higher.

\section{Conclusion}

To sum up, the majority of higher vocational colleges should face up to the significance of double innovation education, analyze the integration of sports spirit and entrepreneurship, and constantly use new ideas and methods to create a new innovation and entrepreneurship education with both scientific and modern characteristics. Normality, while enhancing students' sports spirit, provides assistance to the development of students' innovative awareness and entrepreneurial qualities, so that they can achieve higher levels of development in the future, and show their innovative vitality, effectively promoting socialist construction matters.

\section{References}

[1] Zeng YN. Research on the cultivation of innovation and entrepreneurship spirit of vocational college students in the new era[D]. Jiangxi Science and Technology Vocational College, 2020.

[2] Liu W, Zhu ZJ. Research on the construction of innovation and entrepreneurship campus culture in higher vocational sports colleges[J]. Journal of Shaoguan University, 2016, 37(10): 6064.

[3] Xia P. Investigation and research on the employment situation of graduates in sports vocational colleges -- Taking Fujian sports vocational and technical college as an example [J]. Heilongjiang Science and Technology Information, 2009(32):144. 